\title{
Ventricular fibrillation after inadvertent intravascular injection of ropivacaine
}

\author{
Márcio Galindo Kiuchi ${ }^{*}$, Guilherme Miglioli Lobato ${ }^{2}$ Luis Marcelo Rodrigues Paz ${ }^{1}$ and Shaojie Chen ${ }^{3}$ \\ ${ }^{1}$ Artificial Cardiac Stimulation Division, Department of Medicine, Hospital e Clínica São Gonçalo, São Gonçalo, RJ, Brazil \\ ${ }^{2}$ Anesthesiology Division, Department of Medicine, Hospital e Clínica São Gonçalo, São Gonçalo, RJ, Brazil \\ ${ }^{3}$ Department of Cardiology, Shanghai First People's Hospital, Shanghai Jiao Tong University School of Medicine, Shanghai, China
}

\section{Case report}

Premature ventricular complexes (PVCs) are very usual, looking most commonly in subjects with hypertension, obesity, sleep apnea, and structural heart disease [1]. In general, PVCs in the structurally normal heart are considered benign [2] though they have been associated with a more than the two-fold upper risk of cardiovascular complications, including stroke [3] and death [4]. Reentry is the likely mechanism for PVCs originating from regions of fibrosis or infiltration in cardiomyopathies such as ischemic heart disease, arrhythmogenic right ventricular cardiomyopathy, sarcoidosis, Chagas disease, hypertrophic cardiomyopathies, primary dilated cardiomyopathies, valvular cardiomyopathy, congenital heart disease, muscular dystrophies (e.g., myotonic dystrophy, Emery-Dreifuss muscular dystrophy), and metabolic disorders such as Fabry disease, Pompe disease, Danon disease, and mitochondrial diseases. PVCs can also arise due to reentry around surgical scars. Fascicular PVCs are due to small reentry circuits involving the fascicles $[5,6]$ or to triggered or enhanced automaticity [7].

PVCs have increasingly been recognized as a primary cause for worsening left the ventricular systolic function and heart failure in some patients, once obvious causes such as cardiac ischemia, valvular disease, toxic metabolic or infiltrative diseases, and persistent tachycardia has been excluded. The pathogenesis of PVC-mediated cardiomyopathy is uncertain, and hypotheses include ventricular dyssynchrony, hemodynamic impairment, increased oxygen demand, autonomic dysregulation, alterations in intracellular calcium handling, and altered heart rate (HR) dynamics [8,9]. Though PVCs are fairly infrequent and asymptomatic in most cases; some patients may experience more frequent PVCs and symptoms such as palpitations, chest pain, and dyspnea. The spectrum of benign outflow tract PVCs ranges from single PVCs to repetitive non-sustained ventricular tachycardia (NSVT) to paroxysmal sustained ventricular tachycardia [10]. In rare cases, short-coupled right ventricular outflow tract PVCs can trigger polymorphic ventricular tachycardia [11], while even shorter-coupled PVCs often originating from the fascicular system or papillary muscles can trigger ventricular fibrillation $[7,12]$.

In this case, we dscribe a male patient, 57 years old, with controlled hypertension, with coronary artery, submitted to myocardial revascularization surgery previously, without a prior clinical history of acute myocardial infarction, referred by his attending physician. The patient was in use of acetylsalicylic acid $100 \mathrm{mg}$ daily, telmisartan $40 \mathrm{mg}$ daily and nebivolol $5 \mathrm{mg}$ daily. During the surgery to remove nephrolithiasis, he presented sustained ventricular tachycardia followed by ventricular fibrillation, being defibrillated and the procedure was interrupted. The abdominal ultrasonography had showed left an inguinal hernia containing sigmoid colon loop, with diverticulosis and fat. The basal eletrocardiogram (ECG) presented sinus rhythm, the zone of necrosis in DIII lead, and septal ectopic beats from the left sided ventricular septum. The 24-hour Holter monitoring showed sinus rhythm, with minimum - average - maximum heart rate (HR) of 42, 72 and $106 \mathrm{bpm}$, respectively, as well as, 5752 polymorphic ventricular ectopic beats and 3 episodes of non-sustained ventricular tachycardya, being the highest composed 13 beats at $164 \mathrm{bpm}$. The tranthoracic echocardiogram showed an acinetic zone on the lower wall with a preserved left ventricular ejection fraction. The coronary angiography did not present any new obstruction, and the bridges were patent. As we did not have the records of sustained ventricular tachycardia followed by ventricular fibrillation, the group opted for the electrophysiological study (EPS), that showed HV interval $=63 \mathrm{~ms}$ defining the presence of His-Purkinje conduction disorder, and the programmed ventricular pacing at the 600,500 and $430 \mathrm{~ms}$ command cycles with up to 3 coupled extrastimuli at the right ventricle tip induced sustained ventricular tachycardia, even the patient using the $\beta$-blocker. The patient was cardioverted, the sinus rhythm was reestablished, and the procedure was finnished. Due to the serious illness was actually defined the need for the patient to undergo the implant automatic implantable cardioverter defibrillator (ICD).

The patient remained hospitalized and a few days later was submitted to the implantation of the ICD-DR. The patient was positioned in dorsal decubitus submitted to sedation by the anesthesiologist, and 2 $\mathrm{g}$ of vancomycin intravenous was administered. The local anesthesia was performed with $20 \mathrm{~mL}$ of ropivaine $7.5 \%$ and an incision in the left pectoral region was made, subsequently dissection by planes, and the left pectoral subcutaneous pocket was created. During the injection of the local anesthetic an inadvertent intravascular injection of ropivacaine $7.5 \%$ ocurred and sustained polymorphic ventricular tachycardia followed by ventricular fibrillation was triggered, the patient was promptly defibrillated, and sinus rhythm was maintained (Figure 1A and 1B), besides $300 \mathrm{mg}$ of intravenous amiodarone had been infused in order to complete the procedure. The rest of the surgery took place without any further complication, the ICD-DR was implanted successfully (Figure 2), and the patient was taken to the intensive care unit to be monitored continuously.

Correspondence to: Márcio Galindo Kiuchi, Rua Cel. Moreira César, 138 Centro, São Gonçalo - Rio de Janeiro - Brazil. ZIP-CODE: 24440-400, Tel/Fax: +55 (21) 26047744; E-mail: marciokiuchi@gmail.com

Received: April 10, 2017; Accepted: May 04, 2017; Published: May 08, 2017 
(A)

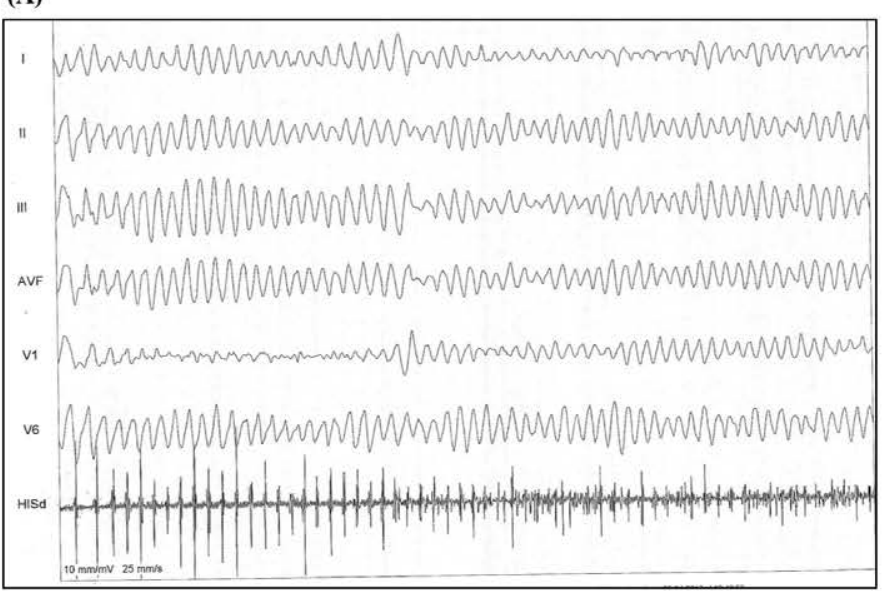

(B)

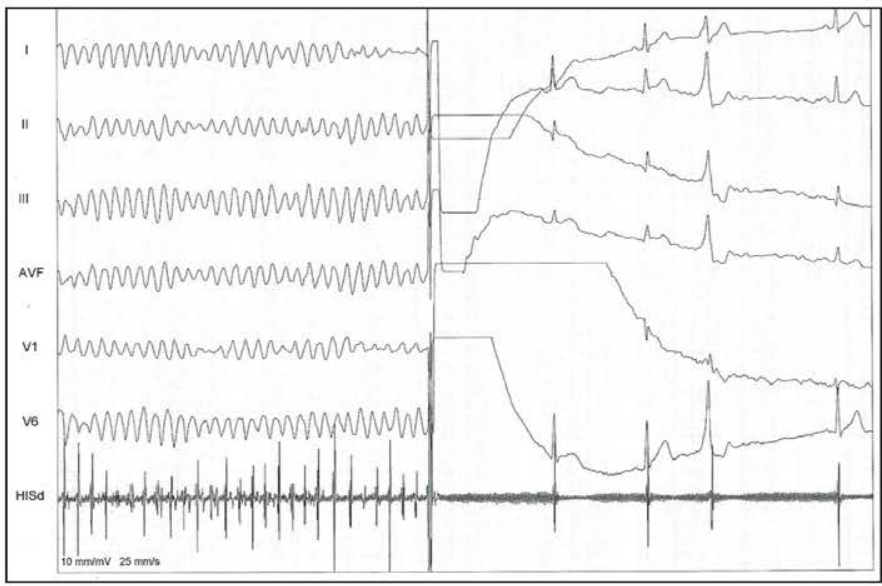

Figure 1. During the injection of the local anesthetic an inadvertent intravascular injection of ropivacaine $7.5 \%$ ocurred, and (A) sustained polymorphic ventricular tachycardia followed by ventricular fibrillation was triggered, (B) the patient was promptly defibrillated, and sinus rhythm was maintained

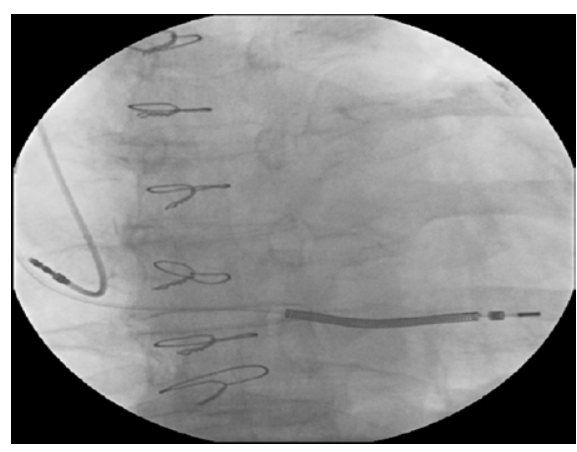

Figure 2. Automatic implantable cardioverter defibrillator (ICD) already implanted.

Toxic systemic reactions involve, primarily, the central nervous system (CNS) and the cardiovascular system. Such reactions are caused by the high blood concentration of the local anesthetic, which may occur due to intravascular (accidental) injection, overdosage or by exceptionally rapid absorption of highly vascularized areas. CNS reactions are similar for all amide-type local anesthetics, whereas cardiac reactions are more drug-dependent, both quantitatively and qualitatively [13]. Toxicity of the cardiovascular system can be seen in severe cases and, in general, is preceded by signs of CNS toxicity. In patients under heavy sedation or receiving general anesthesia, the prodromal symptoms of the CNS may be absent. Hypotension, bradycardia, arrhythmia and even cardiac arrest may occur as a result of high systemic concentrations of local anesthetics, but rare cases of cardiac arrest occurred without prodromal effects of the CNS [13-15].

Ropivacaine, like other local anesthetics, causes reversible blockage of impulse propagation by nerve fibers, preventing sodium ions from entering through the cell membrane of nerve fibers. Local anesthetics may have similar effects on other excitable membranes, such as in the brain and myocardium. Effects on the heart, measured in vivo in animal studies, have shown that the cardiac toxicity of ropivacaine is lower than that of bupivacaine [13-15].

\section{Acknowledgements}

We would like to thank Pacemed for their technical support.

\section{References}

1. Noheria A, Deshmukh A, Asirvatham SJ (2015) Ablating Premature Ventricular
Complexes: Justification, Techniques, and Outcomes. Methodist Debakey Cardiovasc $J$ 11: 109-120. [Crossref]

2. Kennedy HL, Whitlock JA, Sprague MK, Kennedy LJ, Buckingham TA, et al. (1985) Long-term follow-up of asymptomatic healthy subjects with frequent and complex ventricular ectopy. $N$ Engl J Med 312: 193-197. [Crossref]

3. Agarwal SK, Heiss G, Rautaharju PM, Shahar E, Massing MW, et al. (2010) Premature ventricular complexes and the risk of incident stroke: the Atherosclerosis Risk In Communities (ARIC) Study. Stroke 41: 588-593. [Crossref]

4. Ataklte F, Erqou S, Laukkanen J, Kaptoge S (2013) Meta-analysis of ventricular premature complexes and their relation to cardiac mortality in general populations. $\mathrm{Am}$ J Cardiol 112: 1263-1270. [Crossref]

5. Nogami A (2011) Purkinje-related arrhythmias part I: monomorphic ventricular tachycardias. Pacing Clin Electrophysiol 34: 624-650. [CrossRef]

6. Nogami A, Naito S, Tada H, et al. Demonstration of diastolic and presystolic Purkinje potentials as critical potentials in a macroreentry circuit of verapamil-sensitive idiopathic left ventricular tachycardia. J Am Coll Cardiol 36: 811-823. [Crossref]

7. Scheinman MM (2009) Role of the His-Purkinje system in the genesis of cardiac arrhythmia. Heart Rhythm 6: 1050-1058. [CrossRef]

8. Adams JC, Srivathsan K, Shen WK (2012) Advances in management of premature ventricular contractions. J Interv Card Electrophysiol 35: 137-149. [CrossRef]

9. Lee GK, Klarich KW, Grogan M, Cha YM (2012) Premature ventricular contractioninduced cardiomyopathy: a treatable condition. Circ Arrhythm Electrophysiol 5: 229236. [Crossref]

10. Kim RJ, Iwai S, Markowitz SM, Shah BK, Stein KM, et al. (2007) Clinical and electrophysiological spectrum of idiopathic ventricular outflow tract arrhythmias. $\mathrm{J} \mathrm{Am}$ Coll Cardiol 49: 2035-2043. [Crossref]

11. Noda T, Shimizu W, Taguchi A, Aiba T, Satomi K, et al. (2005) Malignant entity of idiopathic ventricular fibrillation and polymorphic ventricular tachycardia initiated by premature extrasystoles originating from the right ventricular outflow tract. $J \mathrm{Am} \mathrm{Coll}$ Cardiol 46: 1288-1294. [Crossref]

12. Santoro F, Biase LD, Hranitzky P, et al. Ventricular fibrillation triggered by PVCs from papillary muscles: clinical features and ablation. J Cardiovasc Electrophysiol 25: 11581164. [Crossref]

13. McLure HA, Rubin AP (2005) Review of local anaesthetic agents. Minerva Anestesiol 71: 59-74. [CrossRef]

14. Kiuchi MG, Zapata-Sudo G, Trachez MM, Ririe D, Sudo RT (2011) The influence of age on bupivacaine cardiotoxicity. Anesth Analg 112: 574-580. [CrossRef]

15. Becker DE, Reed KL (2012) Local Anesthetics: Review of Pharmacological Considerations. Anesth Prog 59: 90-102. [Crossref]

Copyright: (C2017 Kiuchi MG. This is an open-access article distributed under the terms of the Creative Commons Attribution License, which permits unrestricted use, distribution, and reproduction in any medium, provided the original author and source are credited. 